\title{
Pyrenocine I, a new pyrenocine analog produced by Paecilomyces sp. FKI-3573
}

\author{
Junko Hashida $^{1}$, Megumi Niitsuma ${ }^{1}$, Masato Iwatsuki ${ }^{1}$, Mihoko Mori ${ }^{1,2}$, Aki Ishiyama ${ }^{1}$, Miyuki Namatame ${ }^{1}$, \\ Aki Nishihara-Tsukashima ${ }^{1}$, Kenichi Nonaka ${ }^{1}$, Hideaki Ui ${ }^{1}$, Rokuro Masuma ${ }^{1,2}$, Kazuhiko Otoguro, \\ Haruki Yamada $^{1,2}$, Kazuro Shiomi ${ }^{1,2}$ and Satoshi Ōmura ${ }^{1}$
}

The Journal of Antibiotics (2010) 63, 559-561; doi:10.1038/ja.2010.65; published online 30 June 2010

Keywords: antitrypanosomal activity; citreoviridin; Paecilomyces; pyrenocine

Human African trypanosomiasis, also known as sleeping sickness, is caused by two subspecies of the parasitic protozoan, Trypanosoma brucei. Unique to sub-Saharan Africa, human African trypanosomiasis has, in past epidemics, caused significant and widespread mortality and morbidity. The World Health Organization estimated that human African trypanosomiasis caused 52000 deaths in 2004, projecting a continuing fall to a total of 36000 in 2015 (http://www.dndi.org/). ${ }^{1}$ There are significant problems with the four parenteral drugs currently used for treatment (suramin, pentamidine, eflornithine and melarsoprol) as they are highly toxic, expensive, difficult to administer, and parasite resistance to them is increasing. Although a new combination therapy using drugs was introduced in 2009, only one molecule is currently in clinical development for treatment of human African trypanosomiasis (http://www.dndi.org/). ${ }^{2}$ Therefore, there is an urgent need for new antitrypanosomal drugs that are more effective, safer, affordable easier to use and which, ideally, have a novel mode of action.

Our research group has focused on the screening of antitrypanosomal agents from microbial metabolites. ${ }^{3-5}$ Our ongoing studies have led to the discovery of a novel pyrenocine, pyrenocine I (1), which was isolated from the culture broth of Paecilomyces sp. FKI-3573, along with the known pyrenocines A $(2)^{6}$ and B $(3)^{6}$ and citreoviridin (4) (Figure 1). ${ }^{7}$ All of the compounds exhibit in vitro antitrypanosomal activity. In this article, we report their fermentation, isolation, structure elucidation and antitrypanosomal activity.

Fungal strain FKI-3573 was isolated from a soil sample collected in Hilo, HI, USA. The ITS rDNA sequence of FKI-3573 was a $95.6 \%$ match to Paecilomyces lilacinus ATCC 10114 (GenBank accession number AY213665). From this information, combined with morphological characteristics, FKI-3573 was identified to be a member of the Paecilomyces genus. ${ }^{8}$ A stock culture of strain FKI- 3573 was inoculated into $100 \mathrm{ml}$ of seed medium, consisting of glucose (2.0\%), Polypepton (0.5\%; Nihon Pharmaceutical, Tokyo, Japan), yeast extract $(0.2 \%)$, $\mathrm{KH}_{2} \mathrm{PO}_{4}(0.1 \%), \mathrm{MgSO}_{4} \cdot 7 \mathrm{H}_{2} \mathrm{O}(0.05 \%)$ and agar $(0.1 \%)$, adjusted to
pH 5.7 before sterilization. The mixture was subsequently incubated on a rotary shaker at $27^{\circ} \mathrm{C}$ for 3 days. Seed culture $(1 \mathrm{ml})$ was transferred into each of 10 Erlenmeyer flasks $(500 \mathrm{ml})$ together with $100 \mathrm{ml}$ of production medium containing potato dextrose broth (2.4\%), malt extract $(0.5 \%), \mathrm{Mg}_{3}\left(\mathrm{PO}_{4}\right)_{2} \cdot 8 \mathrm{H}_{2} \mathrm{O}(0.5 \%)$ and agar $(0.1 \%)$. The mixture was adjusted to $\mathrm{pH} 6.0$ before sterilization. Fermentation was carried out on a rotary shaker at $27^{\circ} \mathrm{C}$ for 3 days, followed by stationary culture for 10 days.

The culture broth (1.01) was added 1.01 of EtOH. It was concentrated under reduced pressure after removing the mycelia by centrifugation and filtration. The resulting aqueous solution was extracted with EtOAc and the organic layer was concentrated to dryness in vacuo to afford a yellow solid $(488 \mathrm{mg})$. It was applied to ODS column chromatography (eluted with 20,40 and $60 \%$ aqueous $\mathrm{CH}_{3} \mathrm{CN}$ ). The concentrated $20 \% \mathrm{CH}_{3} \mathrm{CN}$ eluate $(42.8 \mathrm{mg})$ was purified by HPLC (column, Pegasil ODS $(20 \phi \times 250 \mathrm{~mm}$, Senshu Scientific, Tokyo, Japan); mobile phase, $30 \%$ aqueous $\mathrm{CH}_{3} \mathrm{CN}$; flow rate, $5.0 \mathrm{ml} \mathrm{min}^{-1}$; detection, UV at $210 \mathrm{~nm})$. Pyrenocine $\mathrm{B}(\mathbf{3}, 16.2 \mathrm{mg})$ and $\mathbf{1}(3.5 \mathrm{mg})$ were obtained at 16 and $18 \mathrm{~min}$, respectively. The $40 \% \mathrm{CH}_{3} \mathrm{CN}$ eluate $(65 \mathrm{mg})$ was purified by HPLC (column, Pegasil ODS $(20 \phi \times 250 \mathrm{~mm})$; mobile phase, $40 \%$ aqueous $\mathrm{CH}_{3} \mathrm{CN}$ containing $0.1 \% \mathrm{TFA}$; flow rate, $5.0 \mathrm{ml} \mathrm{min}^{-1}$; detection, $\mathrm{UV}$ at $210 \mathrm{~nm}$ ) to yield $15 \mathrm{mg}$ of pyrenocine A (2). The $60 \% \mathrm{CH}_{3} \mathrm{CN}$ eluate $(70 \mathrm{mg}$ ) was also purified by HPLC (column, XBridge Prep C8 (10 $\phi \times 250 \mathrm{~mm}$, Waters, Milford, MA, USA); mobile phase, $32 \%$ aqueous $\mathrm{CH}_{3} \mathrm{CN}$; flow rate, $3.0 \mathrm{ml} \mathrm{min}{ }^{-1}$; detection, $\mathrm{UV}$ at $210 \mathrm{~nm}$ ) to produce $9.9 \mathrm{mg}$ of citreoviridin (4), which was identified by comparison of spectral data with published values. ${ }^{9}$

Compound 1 was obtained as a light yellow amorphous solid $\left([\alpha]_{\mathrm{D}}^{23}=-1.0 ; c=0.1\right.$ in $\mathrm{MeOH} ; \mathrm{UV}(\mathrm{MeOH}) \lambda_{\max }(\varepsilon): 229$ (16000), $289 \mathrm{~nm}$ (4700)). The molecular formula was elucidated to be $\mathrm{C}_{11} \mathrm{H}_{14} \mathrm{O}_{4}$ by HR-FAB-MS (found, $209.0805[\mathrm{M}-\mathrm{H}]^{-}$; calculated, 209.0819 for $\mathrm{C}_{11} \mathrm{H}_{13} \mathrm{O}_{4}$ ). The IR spectrum showed characteristic absorptions at $3431,1697,1633$ and $1558 \mathrm{~cm}^{-1}$, suggesting the 
Table $1{ }^{1} \mathrm{H}$ and ${ }^{13} \mathrm{C}$ NMR data of pyrenocines I, A and $\mathrm{B}$ (in $\mathrm{CDCl}_{3} ;{ }^{1} \mathrm{H}, 300 \mathrm{MHz} ;{ }^{13} \mathrm{C}, 75 \mathrm{MHz}$ )

\begin{tabular}{|c|c|c|c|c|c|c|}
\hline \multirow[b]{2}{*}{ Position } & \multicolumn{3}{|c|}{$\delta_{H}($ int, J in Hz) } & \multicolumn{3}{|c|}{$\delta_{C}$} \\
\hline & Pyrenocine I (1) & Pyrenocine A (2) & Pyrenocine B (3) & 1 & 2 & 3 \\
\hline 3 & $5.47 \mathrm{~s}(1 \mathrm{H})$ & $5.47 \mathrm{~s}(1 \mathrm{H})$ & $5.48 \mathrm{~s}(1 \mathrm{H})$ & 87.8 & 87.7 & 87.8 \\
\hline 4 & & & & 170.1 & 168.7 & 168.2 \\
\hline $4-\mathrm{OCH}_{3}$ & $3.82 \mathrm{~s}(3 \mathrm{H})$ & $3.79 \mathrm{~s}(3 \mathrm{H})$ & $3.86 \mathrm{~s}(3 \mathrm{H})$ & 56.1 & 56.3 & 56.5 \\
\hline $6-\mathrm{CH}_{3}$ & $2.32 \mathrm{~s}(3 \mathrm{H})$ & $2.17 \mathrm{~s}(3 \mathrm{H})$ & $2.27 \mathrm{~s}(3 \mathrm{H})$ & 18.5 & 18.5 & 18.6 \\
\hline $1^{\prime}$ & $6.23 \mathrm{~d}(1 \mathrm{H}, 16.0)$ & & & 118.4 & 190.6 & 201.1 \\
\hline \multirow[t]{2}{*}{$2^{\prime}$} & $5.97 \mathrm{dd}(1 \mathrm{H}, 16.0,6.0)$ & $6.30 \mathrm{dq}(1 \mathrm{H}, 15.5,1.5)$ & Ha: $2.81 \mathrm{dd}(1 \mathrm{H}, 17.5,8.5)$ & 139.8 & 133.1 & 52.8 \\
\hline & & & $\mathrm{Hb}: 2.91 \mathrm{dd}(1 \mathrm{H}, 17.5,3.5)$ & & & \\
\hline $3^{\prime}$ & $4.45 \mathrm{qd}(1 \mathrm{H}, 6.5,6.0)$ & $6.80 \mathrm{dq}(1 \mathrm{H}, 15.5,7.0)$ & $4.30 \mathrm{dqd}(1 \mathrm{H}, 8.5,6.5,3.5)$ & 69.0 & 147.4 & 64.3 \\
\hline $4^{\prime}$ & $1.36 \mathrm{~d}(3 \mathrm{H}, 6.5)$ & $1.96 \mathrm{dd}(3 \mathrm{H}, 7.0,1.5)$ & $1.24 \mathrm{~d}(3 \mathrm{H}, 6.5)$ & 23.5 & 18.2 & 22.7 \\
\hline
\end{tabular}<smiles>COc1cc(=O)oc(C)c1/C=C/[C@@H](C)O</smiles>

pyrenocine I (1)<smiles>C/C=C/C(=O)c1c(OC)cc(=O)oc1C</smiles>

pyrenocine A (2)

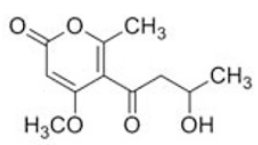

pyrenocine B (3)<smiles>COc1cc(=O)oc(/C=C/C=C/C=C/C(C)=C/[C@@]2(C)OC(C)C(C)(O)C2O)c1C</smiles>

Figure 1 Structures of pyrenocines I, A and B (1-3) and citreoviridin (4).

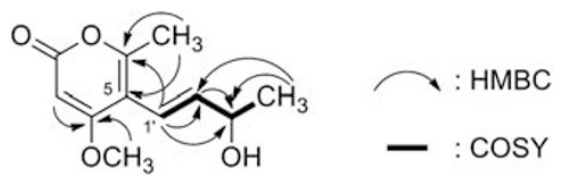

Figure $2{ }^{1} \mathrm{H}-{ }^{1} \mathrm{H}$ COSY and $\mathrm{HMBC}$ correlations of pyrenocine I (1).

Table 2 In vitro antitrypanosomal activity and cytotoxicity of pyrenocines I, A and B and citreoviridin

\begin{tabular}{lccc}
\hline & \multicolumn{2}{c}{ IC $\left._{50}(\mu \mathrm{gm})^{-1}\right)$} & \\
\cline { 2 - 3 } Compound & $\begin{array}{c}\text { Antitrypanosomal activity } \\
\text { T. b.b. GUTat 3.1 }\end{array}$ & $\begin{array}{c}\text { Cytotoxicity } \\
\text { MRC-5 }\end{array}$ & $\begin{array}{c}\text { Selectivity index } \\
\text { MRC-5/GUTat 3.1 }\end{array}$ \\
\hline Pyrenocine I (1) & 1.8 & 8.8 & 4.9 \\
Pyrenocine A (2) & 0.12 & 0.38 & 3.2 \\
Pyrenocine B (3) & 0.76 & 0.98 & 1.3 \\
Citreoviridin (4) & 0.48 & 45 & 94 \\
Suramin & 1.6 & $>100$ & $>63$ \\
\hline
\end{tabular}

presence of an hydroxy group and an $\alpha$-pyrone ring. These physicochemical properties and ${ }^{1} \mathrm{H}$ and ${ }^{13} \mathrm{C}$ NMR spectra of 1 were similar to those of pyrenocines ${ }^{6}$ (Table 1 ). Compound 1 had the same 4-methoxy-6-methyl- $\alpha$-pyrone as $\mathbf{2}$ and 3 , as shown by comparison of the NMR spectra (Table 1). However, the signal of $1^{\prime}$-ketone of $\mathbf{2}$ and 3 was not observed in the ${ }^{13} \mathrm{C}$ NMR spectrum of $\mathbf{1}$. Two olefinic protons $(\delta 5.97$ and 6.23$)$ were observed and their $J$ value $(16.0 \mathrm{~Hz})$ suggested an E-configuration. Correlations of COSY from $1^{\prime}-\mathrm{H}(\delta$ 6.23) through $2^{\prime}-\mathrm{H}(\delta 5.97)$ and $3^{\prime}-\mathrm{H}(\delta 4.45)$ to $4^{\prime}-\mathrm{H}(\delta 1.36)$ revealed that its side chain is a 3 -hydroxy-1-butenyl group. HMBC study established the connection of $\mathrm{C}-1^{\prime}$ of this side chain to $\mathrm{C}-5$ of the $\alpha$-pyrone ring (Figure 2). Thus, the planar structure of the new pyrenocine analog, pyrenocine I (1), was deduced to be 5-[(1E)-3-hydroxy-1-butenyl]-4-methoxy-6-methyl-2H-pyran-2-one.

In vitro antitrypanosomal activity of 1-4 was evaluated using the GUTat 3.1 strain of Trypanosoma brucei brucei, by the method reported earlier. ${ }^{3-5}$ Pyrenocine A (2) showed the most potent antitrypanosomal activity, with an $\mathrm{IC}_{50}$ value of $0.12 \mu \mathrm{g} \mathrm{ml}^{-1}$ (Table 2). Pyrenocine I (1) had a similar antitrypanosomal activity $\left(\mathrm{IC}_{50}=1.8 \mu \mathrm{g} \mathrm{ml}^{-1}\right)$ to the commonly used drug suramin, although it was 10 -fold less active than 2 . However, among 1-3, 1 was the least cytotoxic against a human embryonic lung fibroblast cells, MRC-5 (Table 2). Citreoviridin (4) exhibited antitrypanosomal activity of the same order as 2 and $3\left(\mathrm{IC}_{50}=0.48 \mu \mathrm{g} \mathrm{ml}^{-1}\right)$ but was less cytotoxic than both.

Although pyrenocines show several biological activities, reportedly being phytotoxic, antifungal, antibacterial, cytotoxic and antimalarial, ${ }^{10-13}$ there is hitherto no report of their antitrypanosomal activities. In the past, it has been reported that citreoviridin inhibited the mitochondrial $\mathrm{F}_{1}$-ATPase of Trypanosoma cruzi. ${ }^{14}$ The structural similarity of citreoviridin and pyrenocines suggests that pyrenocines may effect their antitrypanosomal activity through a similar mode of action.

\section{ACKNOWLEDGEMENTS}

This work was supported, in part, by funds from the Drugs for Neglected Diseases initiative (DNDi), Quality Assurance Framework of Higher Education from the Ministry of Education, Culture, Sports, Science and Technology (MEXT), Japan and All Kitasato Project Study (AKPS). We are grateful to Ms Hitomi Sekiguchi and Mr Toshiaki Furusawa for their technical assistance.

1 World Health Organization. The Global Burden of Disease: 2004 Update, WHO, Geneva, (2008).

2 Brun, R., Blum, J., Chappuis, F. \& Burri, C. Human African Trypanosomiasis. Lancet 375, 148-159 (2010).

3 Otoguro, K. et al. Selective and potent in vitro antitrypanosomal activities of ten microbial metabolites. J. Antibiot. 61, 372-378 (2008). 
4 Ishiyama, A. et al. In vitro and in vivo antitrypanosomal activities of two microbial metabolites, KS-505a and alazopeptin. J. Antibiot. 61, 627-632 (2008).

5 Ishiyama, A. et al. In vitro and in vivo antitrypanosomal activities of three peptide antibiotics: leucinostatin $\mathrm{A}$ and $\mathrm{B}$, alamethicin I and tsushimycin. J. Antibiot. 62, 303-308 (2009).

6 Sato, H. et al. X-ray crystal structure of pyrenocine A, a phytotoxin from Pyrenochaeta terrestris. Agric. Biol. Chem. 45, 795-797 (1981).

7 Sakabe, N., Goto, T. \& Hirata, Y. The structure of citreoviridin, a toxic compound produced by Penicillium citreoviride molded on rice. Tetrahedron Lett. 27, 1825-1830 (1964).

8 von Arx, J. A. The Genera of Fungi Sporulating in Pure Culture. 3rd edn. 263 (J. Cramer, Vaduz, 1981).
9 Whang, K., Venkataraman, H., Kim, Y. G. \& Cha, J. K. Total synthesis of (-)-citreoviridin and (+)-citreoviral. J. Org. Chem. 56, 7174-7177 (1991).

10 Krohn, K., Sohrab, M. H., Draeger, S. \& Schulz, B. New pyrenocines from an endophytic fungus. Nat. Prod. Commun. 3, 1689-1692 (2008).

11 Sparace, S. A., Reeder, R. D. \& Khanizadeh, S. Antibiotic activity of the pyrenocines. Can. J. Microbiol. 33, 327-330 (1987).

12 Amagata, T., Minoura, K. \& Numata, A. Cytotoxic metabolites produced by a fungal strain from a Sargassum alga. J. Antibiot. 51, 432-434 (1998).

13 Nilanonta, C. et al. New diketopiperazines from the entomopathogenic fungus Verticillium hemipterigenum BCC 1449. J. Antibiot. 56, 647-651 (2003).

14 Cataldi de Flombaum, M. A. \& Stoppani, A. O. M. Influence of efrapeptin, aurovertin and citreoviridin on the mitochondrial adenosine triphosphatase from Trypanosoma cruzi. Mol. Biochem. Parasitol. 3, 143-155 (1981). 